\title{
O papel das Incertezas - especialmente nas Ciências da Cultura
}

\author{
Tom O. Miller *
}

\begin{abstract}
MILLER, T.O. O papel das Incertezas - especialmente nas Ciências da Cultura.
\end{abstract}
Revista do Museu de Arqueologia e Etnologia, São Paulo, 20: 17-30, 2010.

Resumo: Artigo do ponto de vista de um antropólogo/arqueólogo acerca das diversas mudanças na nossa maneira de encarar a Ciência e o Universo em geral e as suas implicações em termos de consequências: a questão da existência espacio-temporal e efeitos observáveis dos fenômenos que não têm existência físico-objetiva no espaço (por exemplo, informação-organização); historicidade, evolução e irreversibilidade, e a tendência moderna de muitos de procurarem fugir das incertezas. Discutem-se, finalmente, novas perspectivas para a Ciência através da utilização, em vez de rejeição, da hipercomplexidade, além da integração complementar desses conceitos com abordagens tradicionais na nova visão emergente de Ciência.

Palavras-chave: Antropologia Sistêmica e a Segunda Cibernética - Sistemas (Socioculturais) Hipercomplexos - Epistemologia da Ciência.

\section{O papel das incertezas nas ciências socioculturais}

S empre entendemos que a finalidade da Ciência era a de descobrir a ordem inerente ao Universo, apenas aparentemente desordenado. Evidentemente estamos programados para procurar coerência no caos das impressões sensoriais que recebemos do nosso ambiente e, este objetivo científico está de acordo com o nosso "senso comum" de que existe uma ordem fundamen-

${ }^{*}$ )Este ensaio constitui uma tentativa de delinear as dimensões e características das dúvidas suscitadas pela lógica da nova epistemologia cientifica. <tomiller@bol.com.br> (**) Professor aposentado do Departamento de Ciências Sociais (agora Departamento de Antropologia) e do Museu "Câmara Cascudo" da Universidade Federal do Rio Grande do Norte. tal no Universo. Talvez isto se baseie no nosso exercício de tentar classificar os fenômenos observados em termos das nossas categorias semânticas.

Mas, coisas estranhas estão acontecendo. Há mais de trinta e cinco anos, Magoroh Maruyama (1973: 453-4) advertiu que pouca gente está percebendo que estamos passando por uma profunda revolução epistemológica, a primeira desde a época da Grécia antiga. Esta revolução na nossa maneira de ver o Universo envolve uma nova lógica, difícil de expressar porque a nossa lógica depende profundamente da estrutura da nossa lingua.

A Arqueologia moderna tem se colocado na vanguarda das Ciências Sociais (ou seja, Ciências da Cultura) ao ser uma das poucas, fora das Ciências Sociais Aplicadas, a discutir e aplicar tais conceitos. 


\section{O começo das Incertezas}

\section{Causa e Efeito}

Desde os tempos de Aristóteles, entendemos que há uma profunda distinção entre causa e efeito, porque, "é lógico", a causa vem antes e o efeito depois. Na própria estrutura das linguas indoeuropéias, há esta distinção entre passado, presente e futuro. Processos, portanto, devem evoluir neste sentido.

Só que agora estamos entendendo que (como no caso de códigos genéticos) a causa pode estar embutida no efeito e não apenas vice-versa, não se podendo separar uma do outro sem violentar a realidade. Ai está a velha questão teleológica da galinha e o ovo, da planta e a semente.

É que, como disse Maruyama, a causalidade é complexa, intrincada e circular. Mas, como explicar isto numa linguagem de processos lineares? Como explicar a circularidade cíclica ou a bifurcação múltipla dendritica com convergências, tudo em termos lineares? Como explicar a interação hipercomplexa de fenômenos historicamente únicos em termos de generalizações simples sobre recombinações múltiplas de estes princípios simples? Envolve outra lógica e, praticamente, teria de se inventar uma nova linguagem.

\section{O que é Realidade?}

Nós estamos separados da "realidade objetiva" que vivenciamos, ${ }^{1}$ ilhados nos nossos sistemas nervosos com os quais recriamos o Universo dentro das nossas cabeças, tudo de acordo com as impressões sensoriais que recebemos. Naturalmente, essa recriação do Universo acaba sendo de acordo com a nossa maneira de vê-lo dentro das nossas limitações.

(1) Quero pedir desculpas pela quantidade de neologismos que entram neste estudo, pois,

com a nova lógica e o desenvolvimento tão rápido da ciência, hoje em dia, testemunhamos uma verdadeira enxurrada desses novos termos, aos quais não há como fugir. Aliás, a enxurrada nesse campo é muito menor de que no da Informática.
Mais importante ainda, recriamos a sua estrutura de acordo com a estrutura das nossas categorias cognitivas, semânticas e gramaticais; e, de acordo com a nossa mitologia, elaboramos as nossas explanações, socialmente sancionadas, de como o Universo é e como chegou a sê-lo. Para nós, então, o Universo é o que aparenta ser.

Os iluministas revolucionaram a ciência (mas não a epistemologia aristotélica) ao estabelecer dois principios: (1) o de que o começo do conhecimento é a dúvida e, (2) o de que existem maneiras de superar o problema da subjetividade da experiência humana através de (a) observações documentadas e (b) raciocínio disciplinado. Acrescenta-se a isto a ideia mais antiga da sequência de causa $\times$ efeito como fenômenos separáveis, e a do princípio da causalidade externa ao fenômeno em pauta (causa eficiente) como sendo a única aceitável como legitima; e, mais ainda, a da separação abismal entre físico e mental, entre matéria e ideia. Somada isto tudo, ai temos a visão do Universo que dominou o nosso pensamento desde então (e, de fato, ainda domina).

Nem todos, porém, estavam de acordo com tudo, mesmo naquela época. Por exemplo, Mettrie (ver Helvétius 1984) pontificou que não há nada no Universo senão matéria e movimento (energia), enquanto idealistas insistiram na separação entre a "máquina" (ser biológico) e o "espírito" (Descartes 1986). Mas agora sabemos que há mais: estamos tentando entender uma coisa que é, em parte, organização ou informação. Estas produzem efeitos mensuráveis, mas não têm existência material; portanto não estão sujeitas às leis da termodinâmica que, antes, foram consideradas válidas para todos os fenômenos do Universo.

Pois é, agora sabemos que toda essa visão iluminista está profundamente enganada e, que temos de mudar até o nosso próprio modo de pensar - extremamente penoso, até ao ponto de muitos estudiosos preferirem desconhecer os novos rumos da ciência. Mas estamos em crise a nivel mundial porque a acumulação dos erros resultantes dessa visão falsa nos ameaça até de destruição. É urgente que enfrentemos o problema e não fugir dele. 
Não é que as descobertas que a ciência penosamente conseguiu no passado sejam falsas: é que a sua aplicabilidade se limita a apenas alguns aspectos do Universo em determinadas condições, não se aplicando a outros.

Por exemplo: estudiosos indianos antigos, ponderando a natureza do Universo e da existência em geral chegaram à conclusão de que o Universo que vivenciamos pelos nossos sentidos é ilusão, que a realidade é outra e diferente. Depois, os nossos fisicos, ao estudarem a matéria "sólida" em nivel subatômico chegaram a uma conclusão semelhante: a "matéria sólida" é apenas aparência e ilusão, pois é quase totalmente espaço vazio. A microfisica moderna também chega ao ponto de, às vezes, não conseguir distinguir matéria (particulas) e energia, diretamente mensuráveis, do seu comportamento (ondas), apenas mensuráveis indiretamente pelos seus efeitos.

Em seguida, um microfísico desenvolveu um principio que estabelece que no ato da investigação cientifica em geral, relativamente às populações de particulas, o próprio fato de o investigador observar o fenômeno já constitui uma intervenção neste, acarretando mudanças imprevisiveis e irreversiveis. É o princípio da incerteza de Heisenberg, e que faz perfeito sentido para o etnógrafo que examina uma comunidade humana - comentário sobre fenômeno semelhante já havia sido feito pelo etnólogo Bronislaw Malinowski (1922) - e para o arqueólogo procurando a "ideia atrás do homem atrás do artefato". A incerteza é vista como uma medida da quantidade total de alternativas a um determinado evento ou signo disponivel: por mais variedade disponivel, maior incerteza probabilistica sobre a ocorrência do evento.

Mas, recentemente, o físico Fritjof Capra (1977) estendeu o principio mais ainda, observando que, nos fenômenos hipercomplexos ainda não temos meios de aquilatar até que ponto o observador, ao procurar regularidades e principios nos fenômenos observados, acaba impondo uma derivada da sua expectativa.

Segundo Capra (1997: 75), é que as partículas/ondas subatômicas são "ondas de probabilidade" e "Nunca podemos predizer com certeza um evento atômico; apenas podemos prever a probabilidade de sua ocorrência". Ele ainda sustenta que "não lidamos com 'coisas", lidamos com interconexões entre coisas que, por si sós, não têm "existência" e sim, probabilidades de existência. A "realidade" consiste nessas probabilidades de interconexões, as quais, por sua vez, por não terem "existência” material, não têm localização no espaço nem são limitadas pelas leis da termodinâmica. Nesse caso, adverte Capra, você não pode separar a "partícula" sendo observada do "todo" do Universo, inclusive do seu próprio ato de observação:

O comportamento de qualquer parte é determinado por suas conexões nãolocais com o todo, e como não conhecemos precisamente essas conexões, temos que substituir a estreita noção clássica de causa e efeito por um conceito mais amplo, o de causalidade estatística [...]. As probabilidades de eventos atômicos são determinadas pela dinâmica de todo o sistema [...]. Enquanto, na mecânica clássica, as propriedades e o comportamento das partes determinam as propriedades e o comportamento do todo, a situação na mecânica quântica é inversa: é o todo que determina o comportamento das partes (Capra 1997: 80-81).

E assim se reformula e se estende o principio da incerteza, ao observar que da nova perspectiva "o universo começa a se parecer mais com um grande pensamento do que com uma grande máquina."

$\mathrm{Na}$ física atômica, os fenômenos observados só podem ser entendidos como correlações entre vários processos de observação e medição, e o fim dessa cadeia de processos reside sempre na consciência do observador humano [...]. O observador é imprescindivel não só para que as propriedades de um fenômeno atômico sejam observadas, mas também para ocasionar essas proprieda- 
des [...]. O elétron não possui propriedades objetivas independentes da minha mente [...]. Assim, os resultados cientificos que (os cientistas) obtêm e as aplicações tecnológicas que investigam serão condicionados por sua estrutura mental (Capra 1997: 81-82).

Isto tem implicações importantes para a arqueologia, por exemplo, na construção e uso das suas tipologias: destaca-se, deste modo, a importância do uso de medidas probabilisticas de significado e de nivel de confiança, para diminuir a influência da subjetividade na construção das tipologias que devem refletir padrões pré-históricos.

Existe, portanto, uma pluralidade de "realidades objetivas", de acordo com a nossa percepção da situação. A essas realidades podemos intitular, mais acuradamente, não "realidades" e sim "ilusões aparentes". As ilusões aparentes têm existência, pois dizem respeito a aspectos da realidade, as que vivenciamos. A ciência dos séculos XVIII e XIX diz respeito a uma ilusão aparente, a que costumamos chamar de nosso mundo, como percebido pelos nossos sentidos. A fisica newtoniana funciona, mas somente no seu próprio contexto, no contexto de massas em equilibrio. Ai "tudo se torna linear e só há uma solução" (Prigogine 1990: 27).

Quando se muda o contexto, muda-se a natureza da "realidade" e surge outra aparência, outra "ilusão aparente" que se comporta de acordo com outra lógica. Todas essas "ilusões aparentes" fazem parte de uma única "realidade" total. Só que, sob nossa perspectiva, é desconcertante ver o colapso de todas as regras da nossa ilusão vivenciada quando passamos para outros niveis, tais como o nivel do ser humano individual, o da realidade subatômica, o da galáctica ou o da população.

\section{Caos, Organização e Evolução}

A Primeira Lei da Termodinâmica estabelece que a energia do Universo seja constante: não se pode criá-la nem destruí-la, apenas mudar a sua forma ou estado. A Segunda Lei estabelece que todas as transformações energéticas implicam um "desperdício" energético na direção do mais para o menos organizado. Portanto, a finalidade do Universo da Segunda Lei é o caos desorganizado, a dispersão aleatória da energia. Este fenômeno chama-se "entropia" e é um aspecto fundamental do Universo.

No entanto, outros estudiosos (p. ex., Schroedinger 1944) descobriram que, dentro do Universo da entropia, existem fenômenos que captam e incorporam energia entrópica. Esses são os chamados sistemas termodinâmicos, aqueles que captam e incorporam energias entrópicas para estruturar e ampliar a sua própria organização - naturalmente, gastando energia no processo. Este fenômeno se chama "neguentropia", a negação da entropia, ou melhor, a entropia negativa.

Matéria é uma forma de energia, tem existência no espaço e é mensurável. Mas, como já salientamos, existem fenômenos do Universo que não têm existência no espaço, portanto não são diretamente mensuráveis, sendo mensuráveis apenas alguns aspectos dos seus efeitos.

Ilya Prigogine (1990) argumenta que onde se tem a complexidade longe da estabilidade, entram novos processos coerentes. Isto ele chama de princípio da organização. Os processos citados se encontram baseados em probabilidades e, portanto, irreversibilidade. Por que essa coerência deve ser o caso, não sabemos, mas foi amplamente demonstrado que é fato e envolve outros fenômenos não locais no espaço, tais como a "interconexão" das "coisas" com o "todo", o que significa que pode haver uma interconexão atemporal entre fenômenos apesar de qualquer afastamento em espaço físico, o que pela epistemologia anterior seria impossivel. E, ainda, envolve o Princípio da Coerência, segundo os argumentos de Prigogine.

Informação e a organização do caos

Parece que "organização" e "informação" são dois aspectos de uma única realidade fundamental e não material; uma realidade de difícil compreensão porque não faz parte da "ilusão aparente" que vivenciamos. 
Mas, pelo fato de as coisas serem assim, várias resultados se tornam compreensiveis dentro da nova lógica não linear. Por exemplo, a tendência do caos de se organizar quando longe da estabilidade envolve principios que não pertencem à "ilusão aparente" que vivenciamos. Assim, a organização - a informação - não sendo material está, portanto, sem localização no espaço e, consequentemente, não sujeita à Primeira Lei da Termodinâmica. Esta organização pode aumentar no Universo e, de fato, aumenta. Desse modo, torna-se compreensivel a tendência contrária à entropia, a neguentropia que se auto-organiza.

E assim temos a evolução e a história. A história envolve concatenações únicas e altamente complexas na base de poucos principios que, por si sós, podem ser individualmente simples; envolvendo as probabilidades e, portanto, a imprevisibilidade, mas também a irreversibilidade. A informação/organização no Universo pode se acumular porque não tem existência material, apenas efeitos sobre o que venha a ser considerado existência material. Envolve, sim, mudança da estrutura da existência material. Mas, isto é um efeito.

Isso nos remete ao conceito de evolução. Herbert Spencer e outros cientistas sociais perceberam que a evolução não é uma teoria, e sim um imperativo do Universo. É o resultado ou o efeito da atuação destes princípios que estamos examinando. Portanto, como disse Prigogine, o aparecimento da vida (sistemas auto-organizados) é inevitável onde as pré-condições são propicias, e a sua posterior elaboração (neguentropicamente cada vez mais organizada) é igualmente inevitável. A evolução é a própria natureza do Universo da hipercomplexidade auto-organizadora.

\section{Fuga às Incertezas}

Rodeados de tantas dúvidas e incertezas, alguns estudiosos chegaram à conclusão de que, se não se pode mais ter certezas newtonianas das coisas, então a realidade como antes conheciamos efetivamente não existe. Se não se pode mais ter a certeza de que as suas medições (veja bem, no mundo subatômico) refletem a realidade em vez das suas expectativas, então, conclui-se que somente essas expectativas realmente existem.

A filosofia de Fenomenologia (Husserl 1986; Feyerabend 1979), cujas ideias se tornaram bem difundidas sem nome e, praticamente, sem discussão, prega que você só pode provar que existe o seu próprio pensamento, nada mais. Portanto, efetivamente, só existe o seu pensamento, e nada mais. Qualquer outra coisa só pode tomar existência na mente de quem quer acreditar que exista. E, se ninguém acredita numa determinada coisa, como poderia existir? Então, a existência de qualquer fenômeno depende do acreditar ou não, e não de qualquer critério objetivo, pois, se toda a experiência humana é subjetiva, então, ou não existe nenhum mundo objetivo ou, se existir, nos é irrelevante. Para nós, só existem pessoas pensando coisas.

Por esse caminho, também não existe nenhuma distinção entre verdade e mentira, pois as duas são igualmente susceptiveis de serem pensadas, tendo, portanto, existência igual. É o mesmo caso da imaginação, da fantasia etc.

Não pode ser esse o caminho para a ciência alcançar a verdade de um Universo objetivo, pois é a sua própria negação. Assim, nada vale, exatamente porque vale tudo. Não é assim que vamos entender melhor o Universo do qual fazemos parte.

Uma filosofia como a Fenomenologia é o ponto final mais radical do idealismo. Surgiu porque muitos estudiosos estavam procurando uma saida do atoleiro da incerteza no qual a ciência tinha caído, sem regras para dele sair. Mas, em vez de ser a saída, ela é uma espécie de conformismo, uma aceitação de que a incerteza coloca ponto final às indagações sobre o Universo, deixando-nos apenas certeza sobre os nossos pensamentos.

Outra tentativa de procurar uma saida para esse estado de coisas é o Ecletismo, o qual começa no histórico-particularismo boasiano e ainda continua no "pós-moderno" e o "hermenêutico". Ecletismo diz que você não sabe o que é ou não é importante, portanto temos que tratar todos os fenômenos como igualmente importantes. $\mathrm{O}$ 
Universo das coisas humanas e culturais é tão complexo que é improvável que encontremos leis que o governam, se existirem. Portanto, a saída para os ecletistas é se aprofundar no estudo descritivo dos fenômenos, catalogando tudo o que for possivel, pois, algum dia, alguma coisa poderá mostrar que é importante para a compreensão. Até aí, a tentativa de compreensão deve vir através da interpretação criativa da mente do investigador. Aceitam a hipercomplexidade, mas param aquém daquele salto quântico para se aproveitar das possibilidades que ela oferece.

Já para os fenomenologistas, ao considerar que é impossivel uma mente humana observar diretamente qualquer "realidade objetiva", torna-se necessário estudar a fundo as realidades subjetivas e criativas de cada investigador e cada informante.

Nos dois casos, abdica-se de qualquer tentativa de descobrir "leis" do Universo porque tal ação aparenta ser, na prática, humanamente impossivel. Lembre-se que, a essa altura, todos estavam tentando imputar leis absolutas ao Universo, leis que não admitem exceções porque, havendo uma, então não pode haver uma lei. As ciências "exatas" já haviam abandonado essa posição há tempo.

O antropólogo R.H. Lowie protestou, uma vez, indagando como é que pode haver uma "Lei" que diz que em certas circunstâncias ainda não definidas, os objetos podem ter uma tendência de cair, se não subirem. Realmente, se Newton tivesse dado peso igual para fatos como aves voando, nuvens flutuando, folhas no vento e fumaça subindo, tanto quanto para maçãs caindo, não teria chegado a nenhuma "Lei de Corpos Caindo" (gravidade).

\section{Aceitando as Incertezas}

Mas, o pesquisador não precisa desistir, a hipercomplexidade ainda não derrotou a Ciência. Para começar, já foi estabelecido que a distinção iluminista de idealismo $\times$ materialismo é inválida e só pode conduzir ao erro. Feuerbach e Plekhânov mostraram que a vida mental se baseia em fatos materiais (neurônios, sinapses e pequenas cargas elétricas). E as ideias podem não ter existência material por si sós como a informação e a organização em geral mas os seus efeitos são observáveis, como o são os das ondas eletromagnéticas nas quais os elétrons materiais podem se converter. Plekhânov comentou que os que consideram a oposição matéria $\times$ ideia um paradoxo, tendem a incluir um no outro ou de eliminar um ou outro. Assim, alguns materialistas se recusam a considerar "real" a vida mental, enquanto alguns idealistas querem descartar o material.

O Homem tem os dois aspectos: o material (o "ser biológico") e o mental ("espirito") ao mesmo tempo (Descartes 1986), e um não pode existir sem o outro. A "oposição" é um erro e conduz a outros erros, como a oposição de Homem $\times$ Natureza ou Cultura $\times$ Natureza. Como pode o ser humano se opor à natureza se ele faz parte dela? É ficar em oposição a si mesmo, pois a biosfera é um suprassistema do qual os sistemas socioculturais fazem parte.

Por outro lado, não é necessária uma visão tão pessimista das possibilidades do investigador tentando entender o funcionamento do Universo. Uma contribuição positiva do Funcionalismo é que fenômenos podem acontecer diferentemente em contextos diferentes ("condições-limites"). De utilidade negativa é a ideia funcionalista de que a tendência dos organismos e das sociedades é de não mudar: de fato, procuram evitar mudanças, mas não podem deixar de mudar ou então se extinguem quando o contexto se modifica. Uma contribuição positiva do Evolucionismo é que os organismos e a sociedades mudam e que as mudanças podem ser cumulativas. Negativa é a ideia dessa corrente filosófica de que tal mudança (evolução) segue um único programa direcional, e certamente a mudança de patamar de complexidade não é irreversivel (involução). Até o geógrafo árabe Ibn Khaldun, do século XIII, sabia que existiam regularidades nos fenômenos sociais que aparecem somente com grandes amostras de dados - ou seja, que existem regularidades com graus variáveis, mas mensuráveis, de probabilidade de se manifestarem.

Outro aspecto na busca do Santo Graal da Ciência é a questão da verdade. A verdade 
cientifica é aquilo que foi documentado de modo intersubjetivamente a acontecer probabilisticamente em definidas classes de circunstâncias, e que ainda não foi "falseado" (ou seja, desconfirmado por uma observação contrária). O Positivismo e a Fenomenologia concordam em que só se pode perceber o Universo subjetivamente, e o segundo conclui dai que não se pode provar nada mais de que o sujeito está pensando e pode reportar os seus pensamentos.

É verdade que não se pode provar que nada seja verdade absoluta, mas, e isto é importante, podemos provar que muitas proposições não são verídicas e, portanto, podemos eliminá-las.

Aqui entra a "intersubjetividade": ninguém pode observar objetivamente um fenômeno, mas muitos investigadores, como no caso dos cegos tateando o elefante, podem observar o mesmo fenômeno e compartilhar as suas observações. E, mais ainda, cada um deles pode ter a sua porção da verdade - cada um relata a sua ilusão aparente. As observações não podem ser "objetivas"; mas, se podem ser "subjetivas" podem, também, ser "intersubjetivas". Nesse caso, uma observação é cientifica se, e somente se, pode ser duplicada por outro observador que possa confirmar ou desconfirmar a observação.

A ciência moderna trabalha com o consenso da comunidade dos observadores, não apenas com a observação de um deles. A pluralidade de observadores e "escolas" de observadores deve ser vista como complementar em vez de conflitante, e o compartilhamento reciproco dos diferentes aspectos percebidos do Universo pode nos ajudar a nos aproximarmos cada vez mais um pouco à realidade objetiva (o nosso elefante), mesmo ela não sendo alcançável de modo absoluto.

Vejamos a lógica da posição ecletista e fenomenológica de que a verificação ou refutação de observações é irrelevante para as ciências sociais porque o ser pensante é diferente do resto do Universo. Isso significa que o resultado de pular de um prédio alto ou atravessar uma rua movimentada acarreta perigo só em casos individuais; não há regra ou regularidade porque não há lei, só impressões subjetivas e casos excepcionais.
Entretanto, os efeitos das bombas de Hiroshima e Nagasaki não dependiam de os habitantes acreditarem em bombas atômicas. Não acreditavam porque não sabiam que esses artefatos existiam. Mesmo assim morreram.

Só podemos entender o Universo e o papel dos seres vivos, os seres humanos e dos sistemas socioculturais existentes se aceitarmos o total complexo que é ao mesmo tempo material e não material (Morin 1979, 1996), e procurarmos entender os dois aspectos sem negar um ou outro nem incluir um no outro. Como disse genialmente Plekhânov(ver Miller 1991), unidade sem identidade: unidade porque um não pode existir sem o outro, como já observamos; não identidade porque, para estudar e entender um nivel, são necessários métodos e procedimentos diferentes dos que são adequados para estudar e entender o outro.

\section{A hipercomplexidade}

Existe uma abordagem que usa a hipercomplexidade como ponto de partida para a Ciência: a Teoria Geral de Sistemas (TGS), também conhecida como a Segunda Cibernética. A abordagem é altamente relevante para nosso trabalho.

A maior parte do trabalho até agora dentro da Teoria de Sistemas tem sido com sistemas naturais (biológicos) e artificiais, e relativamente pouco com sistemas sociais. As diferenças são muito importantes, tendo, portanto, implicações que não podemos ignorar.

A primeira dessas diferenças a destacar é a historicidade, já mencionada. A historicidade está presente nos sistemas naturais (biológicos), na cumulatividade da informação genética e na informação armazenada na memória. Em Geomorfologia, ela é encontrada na evolução da paisagem, efetivamente um processo irreversivel e certamente cumulativo.

Entretanto, nos sistemas sociais, a cumulatividade da informação socialmente transmitida por códigos simbólicos é de uma ordem de grandeza assustadoramente maior e envolve processos muito mais rápidos. Envolve fatos arqueológica e antropologicamente bem conhecidos, mas com grandes 
implicações para a TGS no tocante a mudanças de programação (mudança cultural), normas de filtragem (ideologia normativa), capacidade de canais de comunicação (linguagem oral e escrita, internet) e de processamento e armazenamento de informação (memória, livros, discos), para mencionar apenas uns poucos casos entre os mais óbvios. Essas implicações exigem um reexame dos aspectos relevantes da TGS, abalizado na nossa experiência nas nossas ciências individuais.

Destacamos como a segunda das diferenças referidas, a complexidade das relações entre os sistemas sociais e dentro destes. Iniciamos com o princípio de que existem sistemas dentro de sistemas e de que o número de niveis hierárquicos de subsistemas e sub-subsistemas é muito grande. Por exemplo, chamamos atenção ao fato de que o sistema sociocultural inclui o subsistema sociopolitico, que por sua vez inclui o sub-subsistema do Estado, este incluindo os diversos poderes e ministérios, que, por sua vez, incluem uma série de cargos, com expectativas de papel apropriadas e, preenchidos por seres humanos individuais.

Em termos das diferenças de sistemas socioculturais, exemplos da maior hipercomplexidade, o psicólogo social F.K. Berrien (1968:

134) discute as implicações de uma sua proposição, que diz que o crescimento segue um "plano" embutido nas subestruturas (células) do sistema inicial modificado por especialização local, o que foi exemplificado por dados bioquímicos (por exemplo, códigos genéticos). Em termos sociais, enfatiza o aparecimento praticamente universal da estrutura piramidal de organizações sociais.

As organizações sociais, com exceção de alguns grupos primários, apresentam uma estrutura hierárquica em forma de árvore [...] A quantidade de poder e de dominação é tanto maior em cada patamar quanto menor o número de individuos que nele estão estabelecidos [...] Os mecanismos homeostáticos de manutenção da organização são muito poderosos (Epstein 1986:17-18).
Isto não é normal entre sistemas naturais, que são mais frequentemente associados por fracos laços colaterais. Isto significa que temos que examinar com muita atenção a natureza dos circuitos de retroação e relações assimétricas de input-output entre diferentes niveis hierárquicos (como, por exemplo, aqueles que permitem a acumulação e armazenamento de energias, tais como capital ou dinheiro, para ação conjunta da sociedade). Temos muito poucas sugestões nesta área deriváveis de estudos de sistemas naturais.

Considera-se, por exemplo, a variedade. Variedade significa informação, ruido, complexidade. Segundo a Lei de Ashby, um sistema poderá controlar outro apenas se contiver uma quantidade igual ou maior de variedade, ou seja, é improvável que um sistema simples consiga capturar e incorporar outro mais complexo. É verdade que, para dar um exemplo, os mongóis de Gênghiz-Cã, depois de se reorganizarem militarmente, conseguiram conquistar (capturar) a China, com ainda mais outros paises, mas não conseguiram absorvê-los (incorporá-los), se mantendo certo tempo como uma classe endógama mas exógena, sobreposta para evitar serem absorvidos pelos seus conquistados. Acabaram sendo expulsos.

Ao discutir a Lei de Ashby, Epstein (1986) "ressalta duas técnicas ou métodos disponiveis ao controlador: aqueles que aumentam a variedade de ações deste numa dada situação e os que simplificam as ações do sistema a ser controlado". Para ilustrar o primeiro caso, Gênghiz-Cã empregou europeus e outros estrangeiros com ideias diferentes para ajudá-lo a administrar a China e outros paises conquistados; como exemplo do segundo, restringiu o acesso de chineses a armas e ao poder administrativo.

Para o pesquisador, que está "jogando" contra a natureza de um sistema social que está "escondendo" as regras do jogo, e a jogada do cientista é de tentar descobri-las, isto significa que é necessário "controlar" a situação aumentando a sua própria variedade (com métodos, técnicas e teorias adequadas) e sem ajudar o parceiro do jogo (a natureza do sistema sendo estudado) a aumentar artificialmente a sua 
própria variedade ao se recusar a levá-la em consideração. A experiência cientifica, aqui, consta em mudar os inputs (entradas) da "caixa preta" (fenômeno cujo funcionamento é desconhecido) sendo estudada, para observar os resultantes outputs (saidas) da mesma.

Em outras palavras, no nosso intuito de descobrir a ordem subjacente ao universo, perdemos muito da nossa capacidade de alcançar os nossos objetivos se tentamos, artificialmente, simplificar a aparência do problema ao nos recusarmos a reconhecer a sua complexidade e a sua variação. A própria variação pode conter pistas para ajudar-nos a explicar a origem das formas das mudanças, tanto quanto outros fenômenos socioculturais.

\section{Linguagem de Dados}

Mas isto não quer dizer que vamos simplesmente transpor a Teoria de Sistemas para qualquer ciência particular e substituir a terminologia e as abordagens tradicionais. Ao contrário, devemos examinar a TGS criticamente à luz da nossa experiência especifica com ciências específicas, como, por exemplo, as de sistemas socioculturais. Nesse sentido, Berrien nega que ele quer um "reducionismo" de tipo lógico-positivista, o que seria incompativel com as nossas ideias de historicidade (cumulatividade), probabilidade, a transformação de inputs em outputs através de caixas-negras, e o aparecimento de mecanismos emergentes (por exemplo, o aparecimento do conceito [ideológico] de "legitimidade", o que permite um Estado emergente de uma Chefia alcançar a estabilidade).

O valor da abordagem sistêmica, como já mencionamos, está na sua capacidade de mostrar que muitos dos fenômenos estudados pelos praticantes de qualquer ciência especializada são casos especificos de fenômenos mais gerais.

A nossa intenção tem sido de tornar claro (o fato de) que um núcleo de definições e fenômenos de sistemas básicos se estende através de toda a hierarquia desde simples até complexo, de não vivo até social. A terminologia especial de diversos niveis de discurso é por demais estabelecida para esperar uma revolução terminológica, mesmo se tal esperança existisse. Os significados da mesma se enriquecem pela descoberta de que são as expressões locais de fenômenos muito mais gerais. Ademais, estas relações conceituais imediatamente estimulam uma busca para outras semelhanças entre sistemas, e a descoberta de fenômenos dentre classes de sistemas que, de outro modo, passariam despercebidos. É esta última consequência que dota uma significação maior à Teoria Geral de Sistemas (Berrien 1968: 116-17).

Para voltar ao problema do operacionalismo na ciência, observamos que não dá para manipular cacos de cerâmica e pontas de projétil quantificados na mesma operação e, se bem que nenhum cientista social faria a besteira de elaborar um trabalho quantificado incluindo clãs matrilineares, linhagens segmentárias e clãs cônicos na mesma operação, não temos a certeza até qual ponto todos os fenômenos chamados de clãs matrilineares ou de linhagens segmentárias, ou de raspadores ou de facas, significam uma única coisa. Sem ter esta certeza, não podemos quantificar para descobrir relações ou regularidades probabilisticas nem fazer estudos comparativos e covariações.

Para os psicólogos, este problema já foi parcialmente resolvido, e podem falar em cálculos de grau de incerteza de operações mentais baseadas nas combinações possiveis de circuitos de neurônios. Mas, mesmo assim, ainda apenas parcialmente. Berrien, por exemplo, comentou que "para intercâmbio social fácil, normas culturais familiares não são apenas uma ajuda; são uma necessidade" (Berrien 1968 115). Mas, em nota de rodapé ele explica que "termos como fácil, redução de tensão, congenial não devem ser interpretados como esforços (de empenhar-se) ou motivações nada mais de que se atribuiria a uma pedra rolando ladeira acidentada abaixo, algum esforço para encontrar um lugar para descan- 
sar." Ótimo. Mas, então, o que realmente devem significar esses termos para o nosso trabalho?

Evidentemente, nós precisamos colocar os nossos conceitos e principios de maneira intersubjetivamente testáveis, e explicitar precisamente o que é que queremos dizer em vez de presumir que todo o mundo sabe o que seja liberdade ou evolução, fase ou lesma, ou qualquer outro fenômeno com o qual os cientistas (e especialmente cientistas sociais) tratam. Estes princípios devem ser definidos de maneira intersubjetivamente testável mesmo que provisórios.

Veja bem, não acreditamos que isto conduzirá a uma substituição de outras técnicas de análise pela matemática; ao contrário, esta é uma técnica (ou conjunto de técnicas) para complementar as outras, mas, por toda a sua utilidade, depende dos fatores já mencionados.

\section{Maior poder explicativo parcimonioso}

A Teoria de Sistemas mostra um novo poder explicativo, manifesto nas mais diversas situações. Por exemplo, aparecem cada vez mais doenças antes desconhecidas, vindas de lugares antes isolados, mas agora desbravados, doenças mutantes devido a erros genéticos provocados por poluentes químicos e radiológicos e por raios solares que passam por "buracos" na camada de ozônio, além de doenças antigas que julgávamos extintas, mas que grassam entre populações pobres, com saneamento deficiente e alta concentração demográfica, o que facilita a transmissão.

A concentração demográfica também torna as pessoas altamente agressivas e a taxa de homicídios, assaltos e outras agressões aumenta. A rapinagem ao ambiente para saquear recursos cada vez mais escassos, acoplada à má distribuição dos produtos processados, provocadas pela natureza do nosso padrão sócio-econômico, criam a fome e a fome cria fraqueza nas defesas imunológicas, de modo a favorecer pandemias; e a tensão da sociedade moderna favorece o consumo de drogas perigosas, alienantes e até fatais. Mau gerenciamento das zonas de mata que deveriam servir para proteção cria desastres climatológicos, hidrográficos, fitogeográficos e ecológicos, vistos atualmente, mas também presentes nos registros arqueológicos.

Tudo isto se torna perfeitamente previsivel em vista de um principio da Teoria Geral de Sistemas, de que, quando um subsistema fornece outputs inaceitáveis, o suprassistema aguarda uma mudança de outputs e, se isto não acontecer, toma medidas para neutralizar ou anular o subsistema perturbador, para prolongar a vida do próprio suprassistema (no caso, a biosfera, o subsistema faltoso sendo nós).

Incertezas sobre o que fazer com as incertezas

Ao se tratar de uma abordagem que explica como chegar a explanações igualmente válidas para sistemas vivos e não, sempre surgem idealistas convictos de que os assuntos que dizem respeito ao Universo em geral nada têm a ver com seres humanos, porque as leis do Universo não dizem respeito a fenômenos mentais. Arqueólogos são, talvez, favorecidos sobre etnólogos, nesta perspectiva, pois a própria natureza das evidências com as quais trabalham não favorece o descartar do aspecto material da cultura.

Feuerbach já explicou há muito tempo que o pensamento envolve pequenas correntes elétricas através de neurônios e as suas sinapses. Energia e matéria. $O$ pensamento não é exceção às leis do Universo, e a transferência de informação está circunscrita pelas mesmas leis e vista através do nosso entendimento da Teoria de Informação, agora reconhecidamente estreitamente ligada à Teoria de Sistemas.

Os idealistas que fazem objeção a estudos dessa natureza alegam que eles desumanizam a humanidade ao fazê-la obedecer às leis do Universo e criam uma visão mecanicista do mesmo, um Universo cegamente girando as suas rodas até o seu fim predestinado, através de leis newtonianas que não admitem alternativas. Nada podia ser mais distante da visão que estamos desenvolvendo aqui.

Para começar, o raciocínio linear, derivado de Aristóteles e característico do nosso pensa- 
mento há 2.500 anos, vê causa-e-efeito como simples e unidirecional: causas semelhantes em condições semelhantes resultam em efeitos semelhantes. Nisto, não há lugar para a circularidade envolvida em causalidade reciproca com múltiplos desdobramentos de circuitos de retroação positiva e negativa, o que conduz a um nivel (se bem que estatisticamente previsivel e mensurável) de incerteza.

Então, baseados nas Leis da Termodinâmica, podemos

ver um sistema cultural como consistindo de matéria, energia e informação. Desta perspectiva, a nossa conceitualização de sistemas reais ou verídicos - ou porções especificas deles - trataria de unidades de análise que têm análogos observáveis e mensuráveis em matéria, energia e informação (Glassow 1972: 292).

No entanto, a Teoria de Sistemas, enquanto abriu uma porta para chegar a uma compreensão maior do Universo, apresentou muito mais de generalizações empíricas válidas para muitas ciências simultaneamente, sem, no entanto, explicar o porquê destas regularidades. Já temos muitos outros casos de regularidades previsiveis que ainda não sabemos o porquê (por exemplo, as tabelas atuariais probabilisticas, que dizem exatamente quantas pessoas de quais categorias sociais vão morrer de quais causas cada dia). Mas isto já é revolucionário: desde que saibamos que existem estas regularidades, já podemos dedicar-nos a procurar, ao pesquisar, o porquê. Antes, isto não era nem possivel porque nem sabiamos que existiam tais regularidades.

Marvin Harris (1970) vem comentando há tempo que a medida da utilidade de uma teoria ou de uma abordagem é a da sua capacidade explanatória, a sua capacidade de explanar (esclarecer) mais fenômenos com menos explanações menos complicadas (o princípio da Parcimônia). A TGS já mostrou isto de maneira impressionante.

Apesar do fato de que um antropólogo, Leslie White, "concebeu a cultura como um sistema termodinâmico vivo numa data compa- rativamente antiga" (Harris 1970: 289; ver White 1959: 33), alguns cientistas, incluindo a maioria dos antropólogos, têm relutado, em geral, em se aproveitar da Teoria de Sistemas, em contraste aos estudiosos de muitas outras ciências sociais. De fato, quem inicialmente mais usou estes conceitos na Antropologia são justamente os estudiosos formados pela "Escola de Michigan", onde Leslie White formou muitos (por exemplo, Marshall Sahlins, Elman Service, David Kaplan e outros em Antropologia, e Lewis Binford em Arqueologia). Em geral, os arqueólogos antropológicos sob a influência de Binford têm desenvolvido a abordagem mais de que os outros antropólogos (ver p. ex., Glassow 1972), embora todos mostrem certa timidez em relação à utilização da terminologia da TGS. Além disso, antropólogos que trabalham com a abordagem ecossistêmica (Ecologia Humana) estão mais acostumados a tal terminologia, pois trabalham em equipe com biólogos (Morán 1979, 1990). Entre os cientistas sociais que abraçaram a abordagem sistêmica destacam-se os das Ciências Sociais Aplicadas, que precisam de resultados em vez de argumentos. É que a Teoria de Sistemas proporciona mais resultados.

\section{Previsibilidade e Incerteza}

A utilização da Teoria de Sistemas como paradigma científico implica em mudanças na estrutura da pesquisa, como aponta Maruyama (1973):

Na nova lógica morfogenética, o desenvolvimento, a heterogenização, e a simbiotização, podem acontecer em muitas direções diversas a partir da mesma condição inicial, por causa dos "loops" (desdobramentos de circuitos) de retroação positiva, amplificadores da diferenciação. A heterogeneidade aumenta.

O grau de incerteza nas tentativas de predição e de retrodição é alto, mas também não entendemos bem as compulsões e limitações que diminuem o número de alternativas disponiveis em determinado estágio de um 
processo ou fenômeno concreto - veja, como exemplos, o Princípio da Limitação das Possibilidades e o Principio da Coerência (ver Miller 2009: Anexos). Por enquanto, só podemos identificar os fatores e parâmetros nos processos depois do fato, não antes.

No entanto, continuamos a insistir no fato de que a convergência realmente observável no mundo dos acontecimentos históricos e arqueológicos concretos seja muito maior do que a incerteza calculável daria para esperar. Isto significa que - tão longe de um Universo caótico quanto de um mecanicista, temos, realmente, um Universo coerente com leis invariáveis interagindo complexamente em casos ou situações historicamente únicos. Acreditamos que, ao aprender mais sobre como os sistemas se comportam, podemos aumentar o grau de probabilidade da nossa previsibilidade, ao controlar ou identificar tais limitações e compulsões.

Até agora o poder preditivo das teorias sociais tem sido bastante baixo em relação ao de outras ciências. Nem sabiamos o porquê, apenas tentamos escolher teorias com maior ou menor valor preditivo, às vezes sendo ainda que tal valor só se desse em determinados contextos. Com esta perspectiva, não queremos alegar que já aumentou o nosso poder preditivo nas ciências sociais. Afirmamos que já temos uma indicação de onde devemos procurar a informação sobre quais os fatores que limitam ou permitem certa probabilidade relativa de previsibilidade.

Ao comparar casos homólogos, podemos medir a probabilidade relativa de determinado output, e ao examinar estruturas e estados de componentes dos sistemas envolvidos, vislumbrar um pouco mais da dinâmica da situação de que antes. $O$ primeiro passo, em comparação com o passado, é gigantesco: agora podemos começar a definir fatores relevantes que antes nem enxergávamos.

Para finalizar, esperamos ter mostrado que a abordagem sistêmica nos proporciona uma armação única dentro da qual qualquer assunto deste Universo que quisermos examinar torna-se mais compreensivel porque se encaixa com todos os outros, dentro de principios válidos para todos. Nunca antes a ciência podia fazer isto. E a incerteza faz parte disto, tanto que, ao não levar em contra a hipercomplexidade dos fenômenos sob o nosso escrutinio, perdemos muito da nossa capacidade de eventualmente compreendê-los. Não devemos ter medo da incerteza: ela não é uma derrota para a ciência. A inclusão dela nas nossas ponderações sobre o Universo é mais um passo na direção de compreender o mesmo.

Ao mesmo tempo, não podemos esquecer que a TGS é uma abordagem, um programa para pesquisa, não uma resposta às nossas indagações. Não oferece soluções para os nossos enigmas, mostra como procurá-los. 
MILLER, T.O. The uses of Uncertainty - particularly in the Sciences of Culture. Revista do Museu de Arqueologia e Etnologia, São Paulo, 20: 17-30, 2010.

Abstract: Here we express the view of an archaeological anthropologist who examines a series of changes in our way of seeing Science and the Universe in general, and, the implications of these in terms of consequences: the problem of spatial-temporal existence and observable effects of phenomena which have no such existence (such as information-organization); historicity, evolution and irreversibility, and the modern tendency of many to seek refuge from the uncertainties through philosophical alienation. Finally, it discusses new perspectives for Science through the use of hyper-complexity, instead of its rejection, and with the integration of these concepts with older ones in an emerging new vision of Science.

Keywords: Systemic Anthropology and the Second Cybernetics - Sociocultural Systems - Hyper complexity - Epistemology of Science.

\section{Referências bibliográficas}

BERRIEN, F.K.

1968 General and Social Systems. New Brunswick: Rutgers University Press.

CAPRA, F.

1977 O Ponto de Mutação, 20ª Ed., São Paulo: Cultrix.

DESCARTES, R.

1986 Discurso do Método. Rio de Janeiro: EdiOuro (Coleção Universidade).

EPSTEIN, I.

1986 Cibernética. São Paulo: Ática. (Principios).

FEYERABEND, P.

1979 Consolando o Especialista. In: Lakatos, I.; Musgrave, A. (Eds.) A critica e o desenvolvimento do conhecimento, São Paulo: Cultrix; EDUSP: 244-84.

GLASSOW, M.A.

1972 Changes in the adaptations of Southwestern Basketmakers: a Systems Perspective In: Leone, M. (Ed.) Contemporary Archaeology. Carbondale: Southern Illinois University Press.

HARRIS, M.

1970 Cultural Materialism: The Struggle for a Science of Culture. New York: Random House.

HELVÉTIUS, CL-A.

1984 In: Condillac, Helvétius e Degérando. 3a ed. São Paulo: Abril Cultural. (Os Pensadores)
HUSSERL, E.

1986 A Ideia da Fenomenologia. Lisboa: Edições 70. MALINOWSKI, B.

1922 Argonauts of the Western Pacific. London: Routledge \& Kegan Paul.

MARUYAMA, M.

1973 The epistemology of Prigogine and its implications for the Social Sciences. Current Anthropology, 19 (2): 432-34.

MILLER, T.O,

1991 Do presente ao passado. In: Anais da Reunião de Antropólogos do norte e do nordeste, 2. Recife, UFPE, Brasilia: CNPq; Rio de Janeiro: FINEP/ABA: 525-549.

2009 A Segunda Revolução Científica: Como o pensa mento sobre o Universo chegou a se transfigurar nos últimos anos. Natal: Editora da UFRN.

s.d. Sistemas Socioculturais. Natal: Editora da UFRN, no prelo.

MORÁN, E.

1979 Human adaptability: an introduction to Ecological Anthropology. North Scrituate, Mass.: Duxbury.

1990 A Ecologia Humana das Populações da Amazônia. Petrópolis: Vozes.

MORIN, E.

1979 O enigma do homem. Rio de Janeiro: Zahar.

1996 Ciência com consciência. Rio de Janeiro: Bertrand Brasil. 
O papel das Incertezas - especialmente nas Ciências da Cultura.

Revista do Museu de Arqueologia e Etnologia, São Paulo, 20: 17-30, 2010.

\section{PLEKHÂNOV, G.}

1989 Os princípios fundamentais do Marxismo, 2a Ed., São Paulo: Hucitec.

PRIGOGINE, I.

1990 O nascimento do tempo. Lisboa: Edições 70.

\section{SCHRÖDINGER, E.}

1944 What is Life?. Cambridge: Cambridge University Press.

WHITE, L.

1959 The evolution of culture. New York: McGraw-Hill.

Recebido para publicação em 17 de junho de 2010. 